\title{
Study on the consolidation properties of soft soil distributed in the North Center coastal area of Vietnam
}

\author{
Son Truong Bui 1, ${ }^{*}$, Nu Thi Nguyen 1, Tho Duc Pham ${ }^{2}$, Duong Thanh Nguyen 1 \\ 1 Faculty of Geoscience and Geoengineering, Hanoi University of Mining and Geology, Viet Nam \\ 2 Faculty of Civil Engineering, Hanoi University of Mining and Geology, Viet Nam
}

\begin{abstract}
ARTICLE INFO
ABSTRACT

Article history: Received 25th Aug. 2020

Revised 19th Oct. 2020

Accepted 31 st Dec. 2020

Keywords:

Consolidation,

Physical properties,

Soft soil.

Consolidation parameters of soft soil play an important role in calculating settlement and soft soil improvement by vertical drainage method (distance, quantity, treatment time). In this study, using oedometer tests, consolidation parameters of some soft soils in the North Central coastal region, Vietnam are clarified. The research results show that the compression index Cc has a strong relationship with the natural water content, liquid limit, dry unit weight, and void ratio of the soil. The consolidation coefficient significantly depends on the applied pressure level, at the over-consolidation stage (normal stress is less than preconsolidation pressure), the consolidation coefficient is high. By contrast, at the normal consolidation stage (normal stress is greater than preconsolidation pressure), the coefficient of consolidation is small. The preconsolidation pressure of soil changes with the distribution depth.
\end{abstract}

Copyright (c 2020 Hanoi University of Mining and Geology. All rights reserved.

${ }^{*}$ Corresponding author

E - mail: buitruongson@humg.edu.vn

DOI: 10.46326/ JMES.HTCS2020.16 


\title{
Tạp chí Khoa học Kỹ thuật Mỏ - Địa chất
}

Trang điện tử: http://tapchi.humg.edu.vn

\section{Nghiên cứu đặc điểm cố kết của đất yếu vùng ven biển Bắc Trung Bộ}

\author{
Bùi Trường Sơn ${ }^{1}{ }^{*}$, Nguyễn Thị Nụ ${ }^{1}$, Phạm Đức Thọ ${ }^{2}$, Nguyễn Thành Dương ${ }^{1}$ \\ ${ }^{1}$ Khoa Khoa học và Kỹ thuật Địa chất, Trường Đại học Mỏ - Địa chất, Việt Nam \\ 2Khoa Xây dựng, Trường Đại học Mỏ - Địa chất, Việt Nam.
}

\section{THÔNGTINBÀI BÁO TÓMTẮT}

Quá trình:

Nhận bài 15/ 02/ 2020

Sửa xong 16/3/2020

Chấp nhận đăng 29/4/2020

Tù̀ khóa:

Chỉ tiêu vật lý,

Cố kết,

Đất yếu.
Các thông số cố kết của đất yếu đóng vai trò quan trong trong việc tính toán độ lún (ốn định, theo thời gian) và tính toán xử lý nền đất yểu bằng các giải pháp thoát nước thẳng đứng (khoảng cách, số lượng, thời gian xử lý). Trong nghiên cúu này, bằng các thí nghiệm nén cố kết ở trong phòng, các thông số cố kết của một số loại đất yếu vung ven biển Bắc Trung Bộ được làm sáng tỏ. Kết quả nghiên cúu cho thấy, chỉ số nén Cc có mối quan hê chặt chẽ với độ ẩm, giới hạn chảy, khối lượg thể tích khô của đất. Hệ số cố kết thay đổi theo cấp áp lực tác dung, ở giai đoạn quá cố kết (áp lực nhỏ hơ áp lực tiền cố kết) thì hê số cố kết lón. Ngược lại, ở giai đoan cố kết thông thường (áp lực lớn hơn áp lực tiền cố kết) hệ số cố kết nhỏ. Âp lực tiền cố kết của đất có sự thay đổi theo chiều sâu trong phạm vi phân bố đất yếu.

(c) 2020 Trường Đại học Mỏ - Địa chất. Tất cả các quyền được bảo đảm.

\section{Mở đầu}

Các thông số cố kết của đất yếu đóng vai trò quan trọng trong việc tính toán độ lún (độ lún ổn định, độ lún theo thời gian) cũng như tính toán thiết kế xử lý nền đất yếu (khoảng cách, số lượng, thời gian xử lý).

Trên thế giới, đặc điểm cố kết của đất yếu đã được nhiều tác giả đi sâu nghiên cứu. Larsson (1986) đã phân tích và chỉ ra những đặc điểm cố kết của đất yếu bằng thí nghiệm trong phòng cũng như quan trắc ngoài hiện trường; hệ thống được

\footnotetext{
*Tác giả liên hệ

E - mail: buitruongson@humg.edu.vn

DOI: 10.46326/ JMES.HTCS2020.16
}

đặc điểm và các thông số đặc trưng cho cố kết thấm. Đây là những định hướng quan trọng cho việc nghiên cứu cố kết của đất yếu. Chu và nnk (2002) đã nghiên cứu tính chất cố kết và tính chất thấm của đất sét biển Singapore và đã chỉ ra hệ số cố kết $\left(\mathrm{C}_{\mathrm{v}}\right)$ của đất biến đổi trong phạm vi rộng phụ thuộc vào ứng suất hữu hiệu và chỉ số OCR. O’Kelly (2006) đã đề cập đến việc nghiên cứu tính chất cố kết theo cả hai phương thẳng đứng và phương ngang của 11 loại đất yếu khác nhau, kết quả cho thấy đặc điểm cấu trúc, và sự bất đồng nhất của đất ảnh hưởng rất lớn tới kết quả thí nghiệm. Bo và nnk (2015) đã chỉ ra sự thay đổi lớn của hệ số cố kết của phần trên, phần giữa và phần dưới đất sét biển tại Singapore do ảnh hưởng của cấu trúc của đất. Al-Khafaji và nnk (2015) đã nhận xét và đánh giá mối quan hệ giữa chỉ số nén và giới 
hạn chảy của đất yếu của các tác giả nghiên cứu trước đó. Nghiên cứu đã chỉ ra các mối quan hệ này bị ảnh hưởng lớn bởi thành phần khoáng vật và có nhiều mối quan hệ có tương quan thấp. Jain và nnk (2015) cũng chỉ ra mối quan hệ giữa chỉ số dẻo và chỉ số nén với mức độ tương quan cao cho đất tại các thung lũng sông tại Ấn Độ. Bo và nnk (2017) nghiên cứu đặc điểm cố kết của đất bằng nhiều thí nghiệm khác nhau như nén cố kết tiêu chuẩn, nén với tốc độ biến dạng không đổi (CRS), nén cố kết theo phương ngang bằng hộp nén Rowe and nén cố kết đẳng hướng cho đất nguyên trạng và đất chế bị lại. Kết quả chỉ ra hệ số nén lún thay đổi trong phạm vi rộng và ảnh hưởng bởi phương pháp thí nghiệm cũng như tốc độ thí nghiệm nén CRS.

Tại Việt Nam, đất yếu phân bố khá rộng rãi ở các đồng bằng như đồng bằng sông Hồng và đồng bằng sông Cửu Long với bề dày biến đổi mạnh (Giao và Hien, 2007; Nu và Thinh, 2020; Nu và nnk, 2020). Các loại đất yếu này là đối tượng bất lợi cho việc xây dựng công trình và cần phải cải tạo bằng các giải pháp xử lý nền đất yếu khác nhau. Nguyễn Thị Nụ và nnk (2011), Nguyễn Thị Nụ (2014) đã nghiên cứu các đặc điểm cố kết của đất loại sét yếu có nguồn gốc $\mathrm{amQ}_{2}{ }^{2-3}$ phân bố ở các tỉnh ven biển đồng bằng sông Cửu Long và đã chỉ ra các đặc điểm cố kết này phụ thuộc vào địa điểm, chiều sâu lấy mẫu cũng như các thành phần muối, hữu cơ trong đất. Nguyễn Thị Nụ và nnk (2020) đã nghiên cứu hệ số cố kết theo phương ngang của một số loại đất khác nhau tại vùng ven biển Việt Nam và chỉ ra tỷ số giữa hệ số cố kết theo phương ngang và theo phương thẳng đứng $\left(\mathrm{C}_{\mathrm{h}} / \mathrm{C}_{\mathrm{v}}\right)$ thay đổi trong phạm vi rộng và phụ thuộc vào loại đất, sự có mặt của hàm lượng hữu cơ cũng như sự tồn tại của các lớp cát xen kẹp trong đất. Nguyễn Thị Nụ và nnk (2020) đã đề cập đến một số tính chất cơ lý ở khu vực Cảng Chân Mây, Thừa Thiên Huế phục vụ xử lý nền bằng đá mi.

Như vậy, có thể thấy các đặc điểm cố kết của đất đã được nghiên cứu bởi các nhà khoa học trên thế giới và Việt Nam. Tuy nhiên, đặc điểm cố kết của đất phụ thuộc vào nhiều yếu tố như loại đất, thành phần vật chất, điều kiện tồn tại cũng như nguồn gốc của đất. Do vậy, vẫn rất cần các nghiên cứu tiếp theo. Hơn nữa, đối với đất yếu vùng ven biển Bắc Trung Bộ, Việt Nam hầu như chưa có công trình nghiên cứu nào đề cập đến việc thiết lập các thông số cố kết của đất với tính chất vật lý của đất. Các công trình thực tế chủ yếu chỉ nghiên cứu riêng lẻ, chưa có các nghiên cứu mang tính hệ thống.

Chính vì vậy, bài báo trình bày kết quả nghiên cứu đặc điểm cố kết của một số loại đất yếu khác nhau phân bố tại khu vực ven biển Bắc Trung Bộ, thiết lập mỗi quan hệ giữa các thông số cố kết của đất với các chỉ tiêu vật lý của đất.

\section{Vật liệu và phương pháp nghiên cứu}

Mẫu đất thí nghiệm được lấy tại một số vị trí khác nhau tại khu vực ven biển Bắc Trung Bộ, bao gồm: Nghi Sơn-Thanh Hóa (TB1), Vinh (TB2), Formusa-Hà Tĩnh (TB3), Huế(TB4). Mẫu được lấy bằng ống thành mỏng, được bảo quản cẩn thận và vận chuyển về phòng thí nghiệm theo TCVN 2683:2012.

Trước hết, các mẫu đất được xác định thành phần hạt, xác định các chỉ tiêu vật lý và phân loại đất theo tiêu chuẩn ASTM D2487. Kết quả nghiên cứu được trình bày ở các Hinh 1,2,3,4.
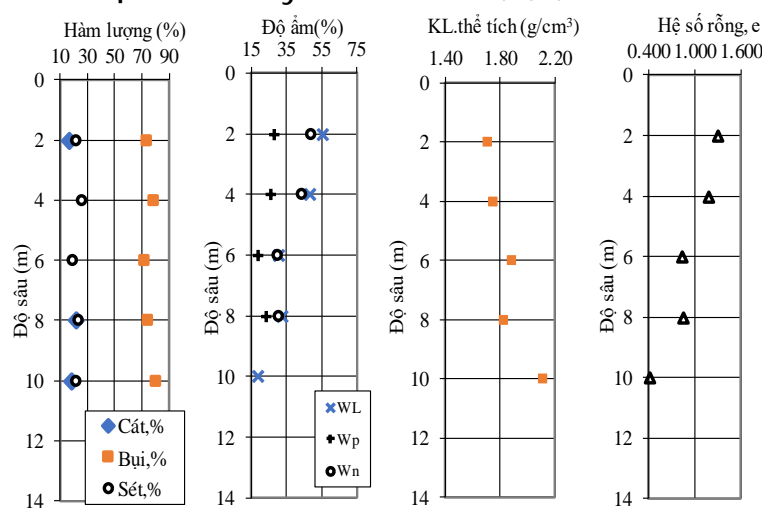

Hình 1. Thành phần hạt và các chỉ tiêu vật lý của đất tại vị trí TB1.
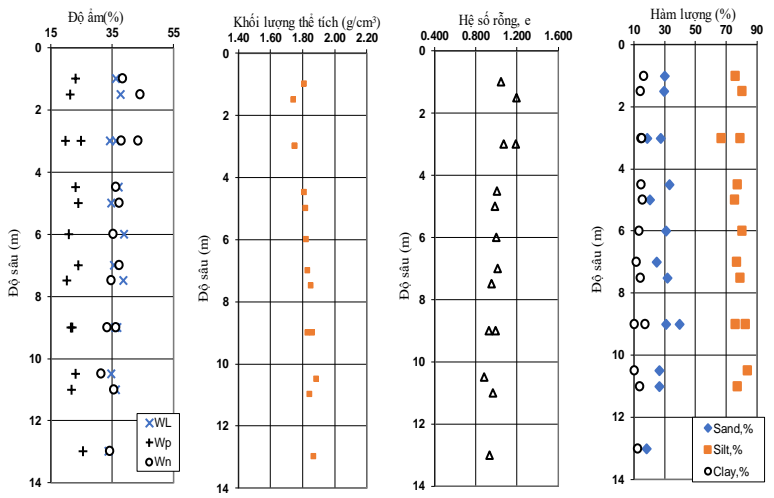

Hình 2. Thành phần hạt và các chỉ tiêu vật lý của đất tại vị trí TB2. 

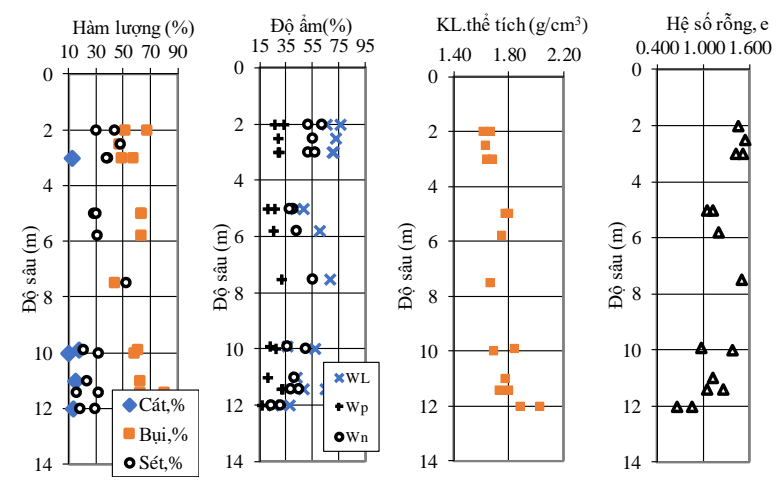

Hình 3. Thành phần hạt và các chỉ tiêu vật lý của đât tại vị tríTB3.
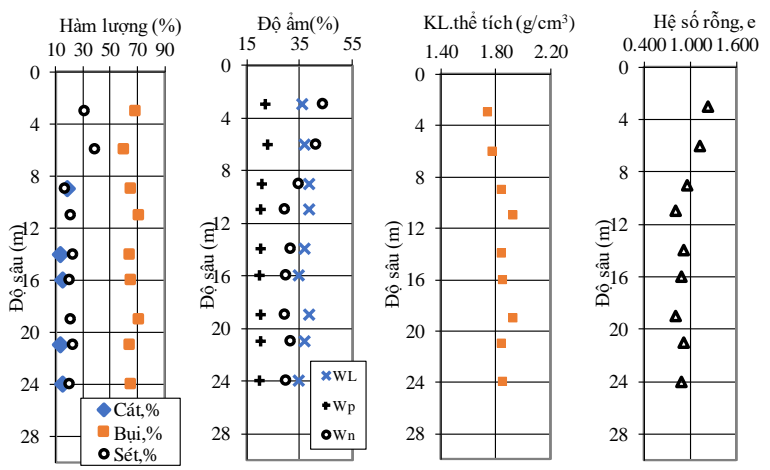

Hình 4. Thành phần hạt và các chỉ tiêu vật lý của đất tại vị trí TB4.

Qua kết quả nghiên cứu cho thấy, đất lấy tại 4 địa điểm khác nhau có trạng thái dẻo chảy đến chảy. Độ ẩm tự nhiên của đất thay đổi thay đổi 29.8\% đến 62.4\%. Tại một số vị trí có giá trị độ ẩm thấp do xen kẹp cát trong đất, nhưng nhìn chung độ ẩm có xu hướng giảm theo chiều sâu. Khối lượng thể tích tự nhiên của đất khá thấp và thay đổi trong khoảng từ $1.62 \mathrm{~g} / \mathrm{cm}^{3}$ đến $1.74 \mathrm{~g} / \mathrm{cm}^{3}$ và có xu hướng tăng dần theo độ sâu. Khi phân tích thành phần hạt cho thấy, hàm lượng hạt bụi là lớn nhất trong các nhóm hat chiếm từ 43.7\% đến $84.2 \%$, hàm lượng hạt sét $(\varangle 0.002 \mathrm{~mm}$ ) thay đổi 10.2 đến $51.9 \%$, hàm lượng hạt cát thay đổi trong khoảng từ 1.0\% đến $39.9 \%$. Hệ số rỗng của đất lớn đều lớn và biến đổi trong khoảng từ 0.881 đến 1.677.

Để nghiên cứu đặc điểm cố kết của đất, thí nghiệm nén cố kết được tiến hành theo tiêu chuẩn ASTM D 2435. Việc lựa chọn cấp áp lực nén tùy thuộc vào chiều sâu của mẫu, cấp áp lực đầu là $12.5 \mathrm{kPa}$, cấp sau gấp đôi cấp trước, cấp áp lực cuối lớn hơn 4 lần áp lực địa tầng tại vị trí lấy mẫu. Từ kết quả thí nghiệm, lập đồ thị quan hệ giữa hệ số rỗng và áp lực tác dụng $\mathrm{e}=\mathrm{f}(\lg \sigma)$, độ lún và thời gian nén ở các cấp áp lực khác nhau $\mathrm{S}=\mathrm{f}$ (lgt). Từ đó xác định được các thông số cố kết của đất như chỉ số nén, chỉ số nở, áp lực tiền cố kết, và hệ số cố kết thẳng đứng. Lập đồ thị quan hệ hệ số cố kết thẳng đứng và áp lực nén $\mathrm{C}_{\mathrm{V}}=\mathrm{f}(\lg \sigma)$ để đánh giá sự thay đổi hệ số cố kết theo áp lực. Thiết lập các đồ thị mối quan hệ giữa chỉ số nén, hệ số cố kết, và các chỉ tiêu vật lý của đất.

\section{Kết quả nghiên cứu và thảo luận}

Kết quả nghiên cứu được trình bày ở bảng 1 và các hình 5,6,7.

Từ kết quả nghiên cứu ở bảng 1 cho thấy, đất yếu tại các vị trí khác nhau có các đặc trưng cố kết khác nhau. Chỉ số nén thay đổi trong phạm vi rộng và phụ thuộc vào vị trí lấy mẫu. Chỉ số nén lún lớn nhất tại vị trị TB4 và thay đổi từ 0.156 đến 0.399 . Tại vị trí TB3 là nhỏ nhất và thay đổi trong khoảng từ 0.153 đến 0.259 . Giá trị chỉ số nén lún trung bình lớn nhất tại vị trí TB4 và nhỏ nhất tại vị trí TB3. Điều này có thể liên quan đến thành phần hạt của đất, ở TB4 hàm lượng hạt sét là nhiều nhất, còn ở TB3 hàm lượng hạt sét là ít nhất. Hệ số cố kết của đất cũng biến đổi trong phạm vi rộng từ $0.276 .10^{-3} \mathrm{~cm}^{2} / \mathrm{s}$ đến $10.10^{-3} \mathrm{~cm}^{2} / \mathrm{s}$ và thay đổi tùy thuộc vào từng vị trí. Giá trị hệ số cố kết nhỏ nhất tại vị trí TB1 và thay đổi trong khoảng $0.561 .10^{-3}$ $\mathrm{cm}^{2} / \mathrm{s}$ đến $0.927 .10^{-3} \mathrm{~cm}^{2} / \mathrm{s}$. Điều này có thể là do tại vị trí TB1 đất có chứa một hàm lượng hữu cơ nhất định, hàm lượng hạt sét nhiều hơn. Giá trị lớn

Bảng 1. Các thông số cố kêt của đất tại các vị trílấy mẫu khác nhau.

\begin{tabular}{|c|c|c|c|c|c|}
\hline TT & Chỉ tiêu & TB1 & TB2 & TB3 & TB4 \\
\hline 1 & $\begin{array}{l}\text { Áp lực } \\
\text { tiền cố } \\
\text { kết, } \mathrm{kPa}\end{array}$ & $\begin{array}{c}64.4 \\
54.4 \div \\
79.0\end{array}$ & $\begin{array}{c}70.0 \\
34.4 \div \\
70.1\end{array}$ & $\begin{array}{c}71.0 \\
52.0 \div \\
105.0\end{array}$ & $\begin{array}{c}151.0 \\
117.0 \div \\
175.0\end{array}$ \\
\hline 2 & $\begin{array}{l}\text { Chỉ số } \\
\text { nén, Cc }\end{array}$ & $\begin{array}{c}0.263 \\
0.009 \\
\quad \div \\
0.355\end{array}$ & $\begin{array}{c}0.294 \\
0.106 \\
\quad \div \\
0.455\end{array}$ & $\begin{array}{c}0.207 \\
0.153 \\
\div \\
0.259\end{array}$ & $\begin{array}{c}0.301 \\
0.156 \div \\
0.399\end{array}$ \\
\hline 3 & $\begin{array}{l}\text { Chỉ số } \\
\text { nở, Cs }\end{array}$ & $\begin{array}{c}0.039 \\
0.008 \\
\div \\
0.062\end{array}$ & $\begin{array}{c}0.028 \\
0.007 \\
\quad \dot{\div} \\
0.058\end{array}$ & $\begin{array}{c}0.033 \\
0.021 \\
\quad \div \\
0.045\end{array}$ & $\begin{array}{c}0.042 \\
0.018 \div \\
0.055\end{array}$ \\
\hline 4 & $\begin{array}{l}\text { Hệ số cố } \\
\text { kêt, } \mathrm{Cv} \\
10^{-3} \mathrm{~cm}^{2} / \mathrm{s}\end{array}$ & $\begin{array}{c}0.682 \\
0.561 \\
\quad \div \\
0.927\end{array}$ & $\begin{array}{c}1.323 \\
0.276 \\
\quad \div \\
3.917\end{array}$ & $\begin{array}{c}1.026 \\
0.454 \\
\quad \div \\
2.195\end{array}$ & $\begin{array}{c}2.95 \\
0.36 \div \\
10.0\end{array}$ \\
\hline
\end{tabular}


nhất tại vị trí TB4 với hệ số cố kết thay đổi trong phạm vi từ $0.36 .10^{-3} \mathrm{~cm}^{2} / \mathrm{s}$ đến $10.10^{-3} \mathrm{~cm}^{2} / \mathrm{s}$. Giá trị lớn nhất là $10.10^{-3} \mathrm{~cm}^{2} / \mathrm{s}$ là do trong mẫu có sự xen kẹp các lớp cát mỏng, tính bất đồng nhất cao. Chỉ số nở thay đổi trong khoảng từ 0.007 đến 0.062. Tỷ số giữa $\mathrm{C}_{\mathrm{s}} / \mathrm{C}_{\mathrm{c}}$ thay đổi trong khoảng 0.044 đến 0.344 . Giá trị áp lực tiền cố kết thay đổi từ 34.4 đến $175 \mathrm{kPa}$ và có xu hướng tăng dần theo chiều sâu.
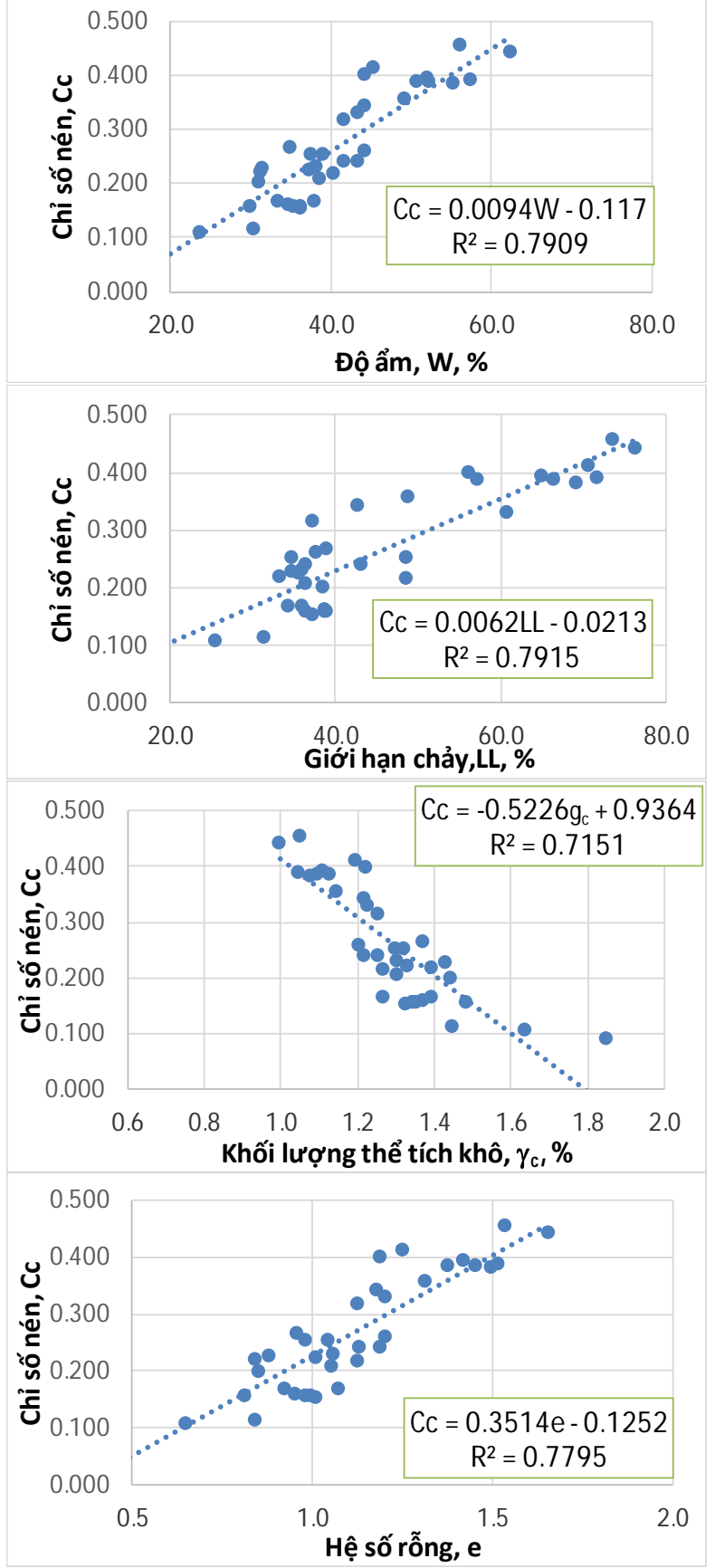

Hình 5. Môi quan hệ giũa chỉ số nén vói các chỉ tiêu vật lý.

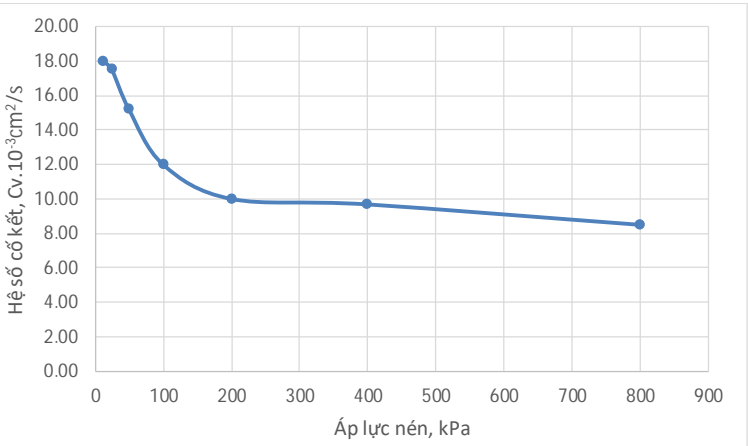

Hình 6. Sự thay đôi hệ số cố kết theo áp lực nén.

Mối quan hệ giữa chỉ số nén và các chỉ tiêu vật lý của đất được thể hiện trên hình 5. Dựa trên hình 5 có thể thấy chỉ số nén lún có tương quan chặt chẽ với các chỉ tiêu độ ẩm tự nhiên, độ ẩm giới hạn chảy của đất, khối lượng thể tích khô và hệ số lỗ rỗng. Theo đó, khi độ ẩm tự nhiên và độ ẩm giới hạn chảy và hệ số lỗ rỗng tăng thì chỉ số nén lún tăng. Kết quả nghiên cứu cho thấy, khi lượng nước trong đất tăng, làm bề dày màng khuếch tán tăng nên, khi đó sẽ làm cho đất lún mạnh hơn. Ngược lại, khi khối lượng thể tích tự nhiên tăng sẽ dẫn tới hệ số nén lún giảm.

Hệ số cố kết xác định theo phương pháp Casagrande thay đổi theo cấp áp lực tác dụng. Khi hệ số rỗng giảm cùng với sự tăng của áp lực hữu hiệu thẳng đứng, hệ số thấm và hệ số nén thể tích giảm nhanh, dẫn đến $\mathrm{C}_{\mathrm{v}}$ giảm dần. Đến các cấp áp lực lớn hơn áp lực tiền cố kết (đến giai đoạn cố kết thông thường) thì hệ số cố kết giảm chậm và ít thay đổi (hình 6). Điều này có thể thấy khi áp lực hữu hiệu tăng, các hạt đất có khuynh hướng sắp xếp chặt hơn, kết quả đối với đất dính, lực liên kết giữa các hạt đất qua màng nước liên kết vật lý tăng lên, chống lại tác dụng của lực ngoài, kháng lại khả năng biến dạng lún của đất (cả về tốc độ và lượng lún), làm hệ số cố kết giảm.
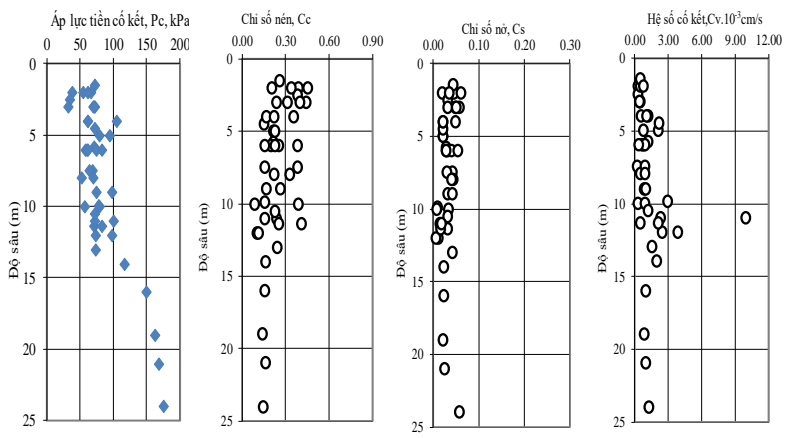

Hình 7. Sự thay đổi các thông số cố kết theo chiều sâu. 
Hình 7 thể hiện sự thay đổi theo chiều sâu của các chỉ tiêu đặc trưng cố kết của đất. Áp lực tiền cố kết có xu hướng tăng theo chiều sâu, chỉ số nén có xu hướng thay đổi theo chiều sâu, và phia dưới từ $15 \mathrm{~m}$ trở xuống có giá trị nhỏ hơn. Hệ số cố kết có sự thay đổi không rõ ràng.

\section{Kết luận}

Kết quả nghiên cứu đặc điểm cố kết của đất tại một số địa điểm khác nhau tại khu vực Bắc Trung Bộ cho thấy sự thay đổi các tính chất cố kết của đất tùy thuộc vào điều kiện tồn tại (vị trí nghiên cứu), có mối quan hệ chặtchẽ với các thông số vật lý của đất và loại đất. Theo đó, chỉ số nén của tăng khi độ ẩm tự nhiên, độ ẩm giới hạn chảy và hệ số lỗ rỗng tăng và giảm khi khối lượng thể tích khô của đất tăng. Hệ số cố kết có sự thay đổi theo cấp áp lực nén, ở giai đoạn cố kết thông thường thì giá trị áp lực cố kết nhỏ. Áp lực tiền cố kết và chỉ số nén có sự thay đổi giảm dần theo chiều sâu. Hệ số cố kết có sự thay đổi không rõ ràng theo chiều sâu.

\section{Lò̀i cảm ơn}

Bài báo nhận được sự tài trợ từ đề tài cấp bộ mã số CT2020.04.MDA.02 thuộc chương trình khoa học và công nghệ cấp Bộ, Bộ Giáo dục và Đào tạo.

\section{Đóng góp của các tác giả}

- Lên ý tưởng: Bùi Trường Sơn, Nguyễn Thị Nụ;

- Thu thập dữ liệu: Nguyễn Thành Dương, Phạm Đức Thọ, Nguyễn Thị Nụ;

- Phân tích dữ liệu: Bùi Trường Sơn, Nguyễn Thị Nụ, Phạm Đức Thọ;

- Viết bản thảo gốc: Bùi Trường Sơn, Nguyễn Thị Nụ, Phạm Đức Thọ, Nguyễn Thành Dương;

- Chỉnh sửa bản thảo: Bùi Trường Sơn, Nguyễn Thị Nụ, Phạm Đức Thọ.

\section{Tài liệu tham khảo}

Al-khafaji, A. W., Maillacheruvu, K. Y., Sainz, M., Neuman, R., (2015). Analysis of empirical compression index equations using the liquid limit. Implementing Innovative Ideas in Structural Engineering and Project Management.

Bo, M.W, Arulrajah, A., Sukmak, P., Horpibulsuk, S. (2015). Mineralogy and geotechnical properties of Singapore marine clay at Changi. Soils and Foundations.55(3):600-613.
Bo, M.W, Choa, V., Chu, J., Arulrajah, A., Horpibulsuk, S. (2017). Laboratory Investigation on the Compressibility of Singapore Marine Clays. Marine Georesources and Geotechnology. Vol.35 (6).

Chu, J., Bo, M.W., Chang, M. F., and Choa,V., (2002). Consolidation and permeability properties of Singapore marine clay. Journal of Geotechnical and Geoenvironmental Engineering, Vol 128 (9), 724-732.

Giao, P.H. Hien, D.H, (2007). Geotechnical characteriztion of soft clay along a highway in the Red River Delta.J Lowl Technol Int 9, 18-27.

Larsson, R. (1986). Consolidation of soft soil, Swedish Geotechnical Institute, Linkiiping, Report No.29.

Jain, V.K., Dixit, M., Chitra, Dr. R. (2015). Correlation of Plasticity Index and Compression Index of Soil. International Journal of Innovations in Engineering and Technology (IJIET). Volume 5 Issue 3 June 2015.263-270.

Nguyễn Thị Nụ, Đỗ Minh Toàn, Nguyễn Viết Tình (2011). Nghiên cứu xác định các thông số cố kết của đất sét $(\mathrm{CL}, \mathrm{CH})$ yếu $\mathrm{amQ}_{2}{ }^{2-3}$ ở Sóc Trăng phục vụ cho việc tính lún và thiết kế xử lý nền đất yếu bằng các thiết bị tiêu thoát nước thẳng đứng. Tạp chí khoa học kỹ thuật Mỏ - Địa chất, 35/ 07/ 2011,tr 32-39.

Nguyễn Thị Nụ (2014). Nghiên cứu đặc tính địa chất công trình của đất loại sét yếu $\mathrm{amQ}_{2}{ }^{2-3}$ phân bố ở các tỉnh ven biển đồng bằng sông Cửu Long phục vụ xử lý nền đường. Luận án tiến sĩ địa chất, Hà Nội.

Nguyễn Thị Nụ, Bùi Trường Sơn, Lê Tiến Dũng (2020). Khả năng xử lý nền đất yếu đê chắn sóng cảng Chân Mây bằng phương pháp thay thế sử dụng đá mi. Tạp chíkhoa học kỹ thuật Mỏ - Địa chất, 61 (4),tr 75-85.

$\mathrm{Nu}$, N.T and Thinh, P.T (2020). Soft soils in the Me Kong Delta of Vietnam. ActuAlscience. 4(1):2431.

Nu, N.T., Toan, D.M., Thinh, P.H, Son, B.T. (2020). Determination of Particles and Minerals Content in Soft Clay Soil of the Mekong Delta Coastal Provinces, Southern Vietnam for 
Inorganic Adhesives Stabilization. Iraqi Journal of Science, 61(4), 791-804.

Nu Nguyen Thi, Bui Truong Son, Do Minh Ngoc (2020). Research on Horizontal Coefficient of Consolidation of Vietnam's Soft Soil. Journal of Engineering, Vol. 2020, 13 pages.
O'Kelly, B.C. (2006). Compression and consolidation anisotropy of some soft soils. Geotechnical and Geological Engineering, 24: 1715-1728.

TCVN 2683:2012, Đất xây dựng - Lấy mẫu, bao gói, vận chuyển và bảo quản mẫu 